\title{
Metabolomics uncovers the role of adipose tissue $P D X K$ in adipogenesis and systemic insulin sensitivity
}

\author{
José María Moreno-Navarrete ${ }^{1,2} \cdot$ Mariona Jove $^{3} \cdot$ Francisco Ortega $^{1,2}$. \\ Gemma Xifra $^{1,2}$ - Wifredo Ricart ${ }^{1,2}$ • Èlia Obis ${ }^{3}$ - Reinald Pamplona ${ }^{3}$. \\ Manuel Portero-Otin ${ }^{3}$. José Manuel Fernández-Real ${ }^{1,2}$
}

Received: 17 September 2015 / Accepted: 17 December 2015 / Published online: 2 February 2016

(C) Springer-Verlag Berlin Heidelberg 2016

\begin{abstract}
Aims/hypothesis We aimed to investigate the potential mechanisms involved in the compromised adipogenesis of visceral (VAT) vs subcutaneous adipose tissue (SAT) using comparative metabolomics. Based on the differentially identified metabolites, we focused on the relationship between the active form of vitamin $\mathrm{B}_{6}$ (pyridoxal 5-phosphate [PLP]), known to be generated through pyridoxal kinase (PDXK), and adipogenesis.

Methods Non-targeted metabolomics analyses were performed in paired VAT and SAT ( $n=14$, discovery cohort). $P D X K$ gene expression was evaluated in two validation cohorts of paired SAT and VAT samples in relation to obesity status and insulin sensitivity, and mechanistically after weight loss in vivo and in 3T3-L1 cells in vitro.
\end{abstract}

José María Moreno-Navarrete and Mariona Jove contributed equally to this work.

Electronic supplementary material The online version of this article (doi:10.1007/s00125-016-3863-1) contains peer-reviewed but unedited supplementary material, which is available to authorised users.

José Manuel Fernández-Real

jmfreal@idibgi.org

1 Department of Diabetes, Endocrinology and Nutrition, Institut d'Investigació Biomèdica de Girona (IdIBGi), Hospital of Girona 'Dr Josep Trueta', Carretera de França s/n, 17007 Girona, Spain

2 Centro de Investigación Biomédica en Red de Fisiopatología de la Obesidad y Nutrición (CIBEROBN), Instituto de Salud Carlos III (ISCIII), Madrid, Spain, http://www.ciberobn.es

3 Department of Experimental Medicine, University of Lleida-Biomedical Research Institute of Lleida (IRBLleida)-PCiTAL, Lleida, Spain
Results Comparative metabolomics showed that PLP was significantly decreased in VAT vs SAT. Concordantly, PDXK mRNA levels were significantly decreased in VAT vs SAT, specifically in adipocytes. The decrease was specially marked in obese individuals. PDXK mRNA levels showed a strong association with adipogenic, lipid-droplet-related and lipogenic genes. At a functional level, systemic insulin sensitivity positively associated with $P D X K$ expression, and surgically-induced weight loss (improving insulin sensitivity) led to increased SAT PDXK mRNA levels in parallel with adipogenic genes. In human pre-adipocytes, $P D X K$ mRNA levels increased during adipocyte differentiation and after administration of peroxisome proliferator-activated receptor- $\gamma$ agonists, and decreased under inflammatory stimuli. Mechanistic studies in 3T3-L1 cells showed that PLP administration resulted in increased adipogenic mRNA markers during early adipogenesis, whereas the PLP antagonist 4deoxypyridoxine exerted opposite effects.

Conclusions/interpretation Overall, these results support the notion that in situ production of PLP is required for physiological adipogenesis.

Keywords Adipogenesis · Insulin sensitivity · Obesity · $P D X K \cdot$ Vitamin $\mathrm{B}_{6}$

$\begin{array}{ll}\text { Abbreviations } \\ \text { 4-DP } & \text { 4-Deoxypyridoxine } \\ \text { MCM } & \text { Macrophage-conditioned medium } \\ \text { PCA } & \text { Principal component analysis } \\ \text { PDXK } & \text { Pyridoxal kinase } \\ \text { PLP } & \text { Pyridoxal 5'-phosphate } \\ \text { PLS-DA } & \text { Partial least-square discriminant analysis } \\ \text { PPAR } & \text { Peroxisome proliferator-activated receptor } \\ \text { RIP140 } & \text { Receptor interacting protein 140 }\end{array}$


SAT Subcutaneous adipose tissue

SVF Stromal vascular fraction

VAT Visceral adipose tissue

\section{Introduction}

Aside from evident differences in anatomical location, adipose tissue depots present in subcutaneous and omental sites are functionally and pathophysiologically different. Obesity-related complications are mainly associated with the presence and amount of omental adipose tissue, leading to the assumption of a distinct deleterious role, as demonstrated in population studies [1]. The reasons for such differences from subcutaneous tissue may arise from differential accumulation of inflammatory cells and a different lipid composition [2]. Omental adipose tissue-derived metabolites, through the anatomical connection mediated by the portal vein, could reach hepatocytes and/or interact with absorbed nutrients [3]. Similarly, metabolic activity at each location differs markedly in sensitivity to endocrine regulators of lipolysis, such as catecholamines and insulin [3]. The differences may be related to obesity-associated growth of adipose tissue, as lipidomic signatures specific to the omental location only arise in obese individuals [2]. The use of systems biology-based approaches (such as genomics, transcriptomics, proteomics and lipidomics) permits a molecular fingerprinting of these tissues. Transcriptomics revealed differentially expressed genes belonging to adipogenesis and lipid metabolism ontogenies both in vivo [4-6] and in cells in vitro [7]. This fits with a differential pattern of protein expression, with locationspecific traits in proteins involved in lipid oxidation-reduction and transport [8].

In contrast to genes and proteins, metabolites provide the most direct evidence of biochemical changes and they can be easily correlated with a given phenotype. Metabolomics based on gas chromatography techniques has been previously tested in adipose tissue from differential locations [9]. Although it is robust, this technique shows a relatively low number of potential candidates when compared with liquid chromatography coupled with high-precision mass spectrometry.

In the present work we demonstrate the existence of specific metabolomic signatures of human omental and subcutaneous adipose tissue (SAT), mainly attributed to selective enrichment in important bioactive compounds. Pyridoxal 5-phosphate (PLP) was one of the most differentially detected metabolites, being significantly decreased in visceral adipose tissue (VAT) vs SAT. Since subsequent analyses showed that $P D X K$ is highly expressed in human adipose tissue, we explored the possible link between $P D X K$ and adipogenesis in human adipose tissue, by employing both a 3T3-L1 mouse cell line and human adipocytes, confirming the importance of PLP and PDXK in adipocyte differentiation.

\section{Methods}

\section{Recruitment of donors for adipose tissue samples}

Cross-sectional studies In the first and second cohort, a group of 196 tissues (101 VAT and 95 SAT) (cohort 1) from participants with normal body weight and different degrees of obesity, with BMI $20-68 \mathrm{~kg} / \mathrm{m}^{2}$, were analysed (for characteristics of cohort, see Table 1). This cohort included 70 paired SAT and VAT samples (eight non-obese and 62 obese participants). In a second cohort of morbidly obese (BMI $>35 \mathrm{~kg} / \mathrm{m}^{2}$ ) individuals with different degrees of insulin activity (measured using hyperinsulinaemic-euglycaemic clamp [6], as detailed in the ESM Methods), 44 paired SAT and VAT samples (cohort 2) were studied (Table 1). The participants were recruited at the Endocrinology Service of the Hospital of Girona Dr Josep Trueta. All were of European descent and reported that their body weight had been stable for at least 3 months before the study. Participants were studied in the post-absorptive state. BMI was calculated as weight (in $\mathrm{kg}$ ) divided by height (in $\mathrm{m}$ ) squared. They had no systemic disease other than obesity and all were free of any infections in the month leading up to the study. Liver diseases (specifically tumours and hepatitis $\mathrm{C}$ infection) and thyroid dysfunction were specifically excluded by biochemical work-up. All participants gave written informed consent, validated and approved by the Ethics committee of the Hospital of Girona Dr Josep Trueta, after the purpose of the study was explained to them.

Samples were obtained from SAT and VAT depots during elective surgical procedures (cholecystectomy, surgery of abdominal hernia and gastric bypass surgery). Samples of adipose tissue were immediately transported to the laboratory (5-10 min). The handling of tissue was carried out under strictly aseptic conditions. Adipose tissue samples were washed in PBS, cut with forceps and scalpel into small pieces $(100 \mathrm{mg})$ and immediately flash-frozen in liquid nitrogen before being stored at $-80^{\circ} \mathrm{C}$. Adipocyte and stromal vascular fraction (SVF) cells were isolated from eight SAT and eight VAT non-frozen samples. These samples were washed three or four times with PBS and suspended in an equal volume of PBS supplemented with $1 \%$ vol./vol. penicillinstreptomycin and $0.1 \%$ (wt/vol.) collagenase type I pre-warmed to $37^{\circ} \mathrm{C}$. The tissue was placed in a shaking water bath at $37^{\circ} \mathrm{C}$ with continuous agitation for $60 \mathrm{~min}$ and centrifuged for $5 \mathrm{~min}$ at $300-500 \mathrm{~g}$ at room temperature. The supernatant fraction, containing mature adipocytes, was collected. The pellet was identified as the SVF. Isolated mature adipocytes and SVF were stored at $-80^{\circ} \mathrm{C}$ for gene expression analysis.

Intervention study The third cohort consisted of 18 obese (BMI $43.67 \pm 4.6 \mathrm{~kg} / \mathrm{m}^{2}$, age $49.1 \pm 7.6$ years $[$ mean $\pm \mathrm{SD}]$ ) 
Table 1 Anthropometric and clinical characteristics of individuals in cohort 1 and cohort 2

\begin{tabular}{|c|c|c|c|}
\hline Characteristic & Non-obese & Obese & $p$ value \\
\hline \multicolumn{4}{|l|}{ Cohort 1} \\
\hline$N, \mathrm{VAT} / \mathrm{SAT}$ & $14 / 12$ & $87 / 83$ & \\
\hline Age, years & $44.6 \pm 12.1$ & $45.4 \pm 10.2$ & 0.8 \\
\hline BMI, $\mathrm{kg} / \mathrm{m}^{2}$ & $26.1 \pm 2.8$ & $44.9 \pm 6.7$ & $<0.0001$ \\
\hline Fasting glucose, $\mathrm{mmol} / \mathrm{l}$ & $4.77(4.44-5.27)$ & $5.32(4.82-6.21)$ & 0.03 \\
\hline Fasting triacylglycerols, $\mathrm{mmol} / \mathrm{l}$ & $1.02(0.76-2.26)$ & $1.19(0.91-1.70)$ & 0.8 \\
\hline HDL-cholesterol, mmol/1 & $1.56(1.16-2.17)$ & $1.34(1.11-1.61)$ & 0.5 \\
\hline VAT $P D X K, \mathrm{RU}$ & $0.095 \pm 0.04$ & $0.074 \pm 0.03$ & 0.04 \\
\hline SAT $P D X K$, RU & $0.138 \pm 0.03$ & $0.139 \pm 0.05$ & 0.9 \\
\hline \multicolumn{4}{|l|}{ Cohort 2} \\
\hline$N$ & 44 & & \\
\hline Age, years & $47.5 \pm 8.6$ & & \\
\hline BMI, $\mathrm{kg} / \mathrm{m}^{2}$ & $44.6 \pm 6.8$ & & \\
\hline Fasting glucose, mmol/1 & $5.41(4.99-5.94)$ & & \\
\hline$M$ value, $\mathrm{mmol} \mathrm{kg}^{-1} \cdot \mathrm{min}^{-1}$ & $0.020 \pm 0.012$ & & \\
\hline Fasting triacylglycerols, $\mathrm{mmol} / \mathrm{l}$ & $1.37(0.95-1.74)$ & & \\
\hline HDL-cholesterol, mmol/1 & $1.18 \pm 0.24$ & & \\
\hline VAT $P D X K, \mathrm{RU}$ & $0.069 \pm 0.03$ & & \\
\hline SAT $P D X K, \mathrm{RU}$ & $0.128 \pm 0.04$ & & \\
\hline
\end{tabular}

Data are means $\pm \mathrm{SD}$ or median (interquartile range)

$\mathrm{RU}$, relative gene expression units individuals of European descent, who underwent bariatric surgery (Roux-en-Y gastric bypass [RYGB]) at the Hospital of Girona Dr Josep Trueta and were part of an ongoing study [6]. Inclusion criteria were age $30-60$ years, BMI $\geq 35 \mathrm{~kg} / \mathrm{m}^{2}$ and ability to understand the study protocol. Exclusion criteria were use of medications able to interfere with insulin's action and history of a chronic systemic disease. Samples from the SAT depot were obtained during bariatric surgery. Postoperative samples of SAT were obtained by subcutaneous biopsy at the mesogastric level 2 years after surgery. Fasting blood samples were obtained on the same day as the biopsy. All participants gave written informed consent, validated and approved by the ethical committee of the Hospital of Girona Dr Josep Trueta, after the purpose of the study was explained to them.

\section{Analytical methods}

Serum glucose concentrations were measured in duplicate by the glucose oxidase method using a Beckman glucose analyser II (Beckman Instruments, Brea, CA, USA). A Roche Hitachi Cobas c711 instrument (Roche, Barcelona, Spain) was used to determine HDL-cholesterol and total serum triacylglycerols. HDL-cholesterol was quantified by a homogeneous enzymatic colorimetric assay through the cholesterol esterase-cholesterol oxidase-peroxidase reaction (Cobas HDLC3). Serum fasting triacylglycerols were measured by an enzymatic, colorimetric method with glycerol phosphate oxidase and peroxidase (Cobas TRIGL).

\section{Non-targeted metabolomics}

Metabolites were analysed in the discovery cohort in 14 paired VAT and SAT samples (four men and ten women) with methanol according to previously described methods [2]. Briefly, 20 volumes (vol./wt) of cold methanol (containing $1 \mu \mathrm{mol} / \mathrm{l}$ butylated hydroxytoluene) were added to 35-50 mg of adipose tissue and homogenised with a Polytron device at $4{ }^{\circ} \mathrm{C}$. Then, 20 volumes of lysis buffer (consisting of $180 \mathrm{mmol} / \mathrm{l} \mathrm{KCl}, 5 \mathrm{mmol} / 1 \mathrm{EDTA}$ and $1 \mathrm{mmol} / \mathrm{l}$ diethylenetriaminepentaacetic acid, $\mathrm{pH}$ 7.3) were added and homogenates were incubated at $-20^{\circ} \mathrm{C}$ for $1 \mathrm{~h}$ and centrifuged at $12,000 \mathrm{~g}$ for $3 \mathrm{~min}$. The supernatant fractions were recovered, evaporated using a Speed Vac (Thermo Fisher Scientific, Barcelona, Spain) and resuspended in $0.4 \%$ vol./vol. acetic acid and methanol (1: 1 vol./vol.).

For the metabolomics studies, an Agilent 1290 LC system coupled to an electrospray ionisation quadrupole time-offlight (ESI-Q-TOF) MS/MS 6520 instrument (Agilent Technologies, Barcelona, Spain) was used. In all cases, $2 \mu \mathrm{l}$ of extracted sample was applied onto a reverse-phase column (Zorbax SB-Aq, $1.8 \mu \mathrm{m} 2.1 \times 50 \mathrm{~mm}$; Agilent Technologies) equipped with a precolumn (Zorba-SB-C8 Rapid Resolution Cartridge, $2.1 \times 30 \mathrm{~mm} 3.5 \mu \mathrm{m}$; Agilent Technologies) with a 
column temperature of $60^{\circ} \mathrm{C}$. The flow rate was $0.6 \mathrm{ml} / \mathrm{min}$. Solvent A was composed of water containing $0.2 \%$ vol. $/$ vol. acetic acid and solvent $\mathrm{B}$ was composed of methanol and $0.2 \%$ acetic acid. The gradient started at $2 \%$ vol./vol. B and increased to $98 \%$ vol./vol. B in $13 \mathrm{~min}$, and then held at $98 \%$ B for 6 min. Post-time was established in $5 \mathrm{~min}$.

Data were collected in positive and negative electrospray mode TOF operated in full-scan mode at $50-1,600 \mathrm{~m} / \mathrm{z}$ in an extended dynamic range ( $2 \mathrm{GHz}$ ), using $\mathrm{N}_{2}$ as the nebuliser gas $\left(10 \mathrm{l} / \mathrm{min}, 350^{\circ} \mathrm{C}\right)$. The capillary voltage was $4,000 \mathrm{~V}$ with a scan rate of $1.5 \mathrm{scan} / \mathrm{s}$. The ESI source used a separate nebuliser for the continuous, low-level $(10 \mathrm{l} / \mathrm{min})$ introduction of reference mass compounds: $121.050873,922.009798$ (positive ion mode) and 119.036320, 966.000725 (negative ion mode), which were used for continuous, online mass calibration. The MassHunter Data Analysis Software (Agilent Technologies) was used to collect the results and the MassHunter Qualitative Analysis Software (Agilent Technologies) was used to obtain the molecular features of the samples, representing different, co-migrating ionic species of a given molecular entity using the Molecular Feature Extractor algorithm (Agilent Technologies), as described [10, 11]. Finally, the MassHunter Mass Profiler Professional Software (Agilent Technologies) was used to perform a non-targeted metabolomic analysis of the extracted features. We selected samples with a minimum absolute abundance of 5,000 counts and with a minimum of two ions. Multiple charge states were not considered. Compounds from different samples were aligned using a retention time (RT) window of $0.1 \% \pm 0.15 \mathrm{~min}$ and a mass window of $5.0 \mathrm{ppm} \pm 2.0 \mathrm{mDa}$. Only common features (found in at least $75 \%$ of the samples at the same condition) were analysed, correcting for individual bias. Data for principal component analysis (PCA) and partial leastsquare discriminant analysis (PLS-DA) were obtained using this software. The masses with significant differences (paired $t$ test, $p<0.05$; Benjamini Hochberg correction for false discovery rate) in abundance were searched against METLIN Metabolite PCD/PCDL database (Agilent Technologies). This database allows the identification of metabolites based on isotope distribution, exact mass and identical chromatographic conditions with authentic standards. Pathway analysis was performed using Metaboanalyst platform [12] and resulting pathways were included in the ConsensusPathDB Interaction database [13].

\section{RNA expression}

RNA purification, gene expression procedures and analyses were performed, as detailed in electronic supplementary material (ESM) Methods and previously described $[6,14,15]$.

\section{Differentiation of human pre-adipocytes}

Isolated human subcutaneous and visceral pre-adipocytes (Zen-Bio, Research Triangle Park, NC, USA) were cultured and differentiated as detailed in ESM Methods.

$\mathrm{TNF} \alpha(100 \mathrm{ng} / \mathrm{ml})$ and macrophage-conditioned medium (MCM, 5\% vol./vol.) from THP-1 cells previously treated with lipopolysaccharide (10 ng/ml, $24 \mathrm{~h}$ ) were added during both SAT and VAT adipocyte differentiation. Otherwise, after adipocyte differentiation (on day 14), SAT fully differentiated adipocytes were incubated with fresh medium (control) or fresh medium containing rosiglitazone $(0.1$ and $1 \mu \mathrm{mol} / \mathrm{l})$. After $48 \mathrm{~h}$ cells were harvested and pellets and supernatant fractions were stored at $-80^{\circ} \mathrm{C}$.

All in vitro experiments using human cells were performed in triplicate and experimenters were blind to outcome assessment.

\section{Mouse 3T3-L1 cell differentiation and mechanistic studies}

The embryonic fibroblast mouse cell line 3T3-L1 (American Type Culture Collection; LGC Standards, Barcelona, Spain) was cultured in DMEM containing $20 \mathrm{mmol} / \mathrm{l}$ glucose, $10 \%$ vol./vol. calf bovine serum, $100 \mathrm{U} / \mathrm{ml}$ penicillin and $100 \mu \mathrm{g} / \mathrm{ml}$ streptomycin. Mycoplasma contamination was not detected in this cell line. During 3T3-L1 adipocyte differentiation, calf bovine serum was replaced with fetal bovine serum. Two days after confluence, insulin $(5 \mu \mathrm{g} / \mathrm{ml})$, dexamethasone $(0.5 \mu \mathrm{mol} / 1)$ and isobutylmethylxanthine $(0.5 \mathrm{mmol} / \mathrm{l})$ mixture was added for 2 days, followed by 5 days with insulin $(5 \mu \mathrm{g} / \mathrm{ml})$ alone, which was replaced on day 5 . Cells were then considered mature adipocytes, harvested on day 7 and stored at $-80^{\circ} \mathrm{C}$ for RNA purification. To demonstrate the functional role of PLP, 4-deoxypyridoxine (4-DP; 5 and $50 \mu \mathrm{mol} / \mathrm{l})$ and PLP $(0.5,5$ and $50 \mu \mathrm{mol} / \mathrm{l})$ administration was performed during adipocyte differentiation. These experiments were performed in triplicate and experimenters were blind to outcome assessment.

\section{Statistical analyses}

Statistical analyses were performed using SPSS 12.0 software. Unless otherwise stated, descriptive results of continuous variables are expressed as mean $\pm \mathrm{SD}$ for Gaussian variables or median and interquartile range. Variables that did not fulfil normal distribution were log transformed to improve symmetry for subsequent analyses. The relationship between variables was analysed by simple correlation (Pearson's test and Spearman's test) and multiple regression analyses in a stepwise manner. For non-targeted metabolomics, a paired $t$ test was used, with Benjamini-Hochberg correction for false discovery rate. Otherwise, one-factor ANOVA with post hoc Bonferroni test, paired $t$ test and unpaired $t$ test were used to 
compare $P D X K$ gene expression according to obesity. A nonparametric test (Mann-Whitney test) was used to analyse in vitro experiments. In all cases, the level of statistical significance was set at $p<0.05$.

\section{Results}

\section{Non-targeted metabolomics discloses a location-specific metabolomics profile}

Non-targeted metabolomics showed that many molecular features (51 downregulated and 513 upregulated in VAT vs SAT, in positive ionisation; 37 downregulated and 98 upregulated in VAT vs SAT in negative ionisation) differed significantly in their concentrations (ESM Dataset 1), as demonstrated by hierarchical clustering, heatmaps and both unsupervised (PCA) and supervised multivariate analyses (PLS-DA) with an accuracy exceeding 95\% (Fig. 1a, b). To reinforce this, we employed alternative classification procedures, such as random forest analyses, which demonstrated an error rate below 18\% (Fig. 1c). Furthermore, the recursive supported vector machine scheme showed a model with a $7.1 \%$ error rate with only five molecular species (Fig. 1d). Multivariate classification procedures indicate a specific profile of metabolites in SAT vs VAT. As indicate both by Random forest analyses (Fig. 1c) and recursive supported vector machine classification (Fig. 1d), a relatively low error of classification could be obtained with few compounds.

Based on accurate mass, isotope distribution and retention time equality with authentic standards, nine metabolites were identified (Table 2). Pathway analyses (ESM Table 1 and ESM Fig. 1) clustered these metabolites across two major networks: one comprising adipocytokine and peroxisome proliferator-activated receptor (PPAR) signalling and the other including vitamin metabolism. Based on very early data [16-19] we focused on vitamin $B_{6}$ metabolism: the levels of vitamin $\mathrm{B}_{6}$ active metabolite PLP were significantly decreased in VAT vs SAT (Fig. 2a). Consistently, in the discovery and validation cohorts, mRNA levels of $P D X K$, encoding the enzyme needed for PLP synthesis, were also detected in human adipose tissue, being significantly downregulated in VAT vs SAT (Fig. 2b, c). Interestingly, $P D X K$ gene expression was positively correlated with PLP levels in SAT (Fig. 2d), but not in VAT (Fig. 2e). PDXK mRNA was significantly enriched in the adipocyte fraction of adipose tissue (Fig. 2f).

\section{PDXK is implicated in adipogenic differentiation in human adipose tissue}

To test whether PDXK could be implied in the adipogenic program of human adipose tissue, we compared its expression with accepted markers of adipogenesis in three independent cohorts. In the discovery cohort (Table 1), PDXK gene expression was significantly associated with expression of adipogenic genes, including $P P A R G$, lipid-droplet-related (CIDEC, PLINI) and lipogenesis-related (FASN, ACACA) genes both in SAT and in VAT (Table 3). Otherwise, $P D X K$ gene expression was negatively associated with TMEM26 mRNA levels (a specific marker of beige adipocytes) and no significant relationships were found with the expression of inflammatory gene markers ( $L E P, I L 6, T N F$ and CD68) (Table 3). VAT PDXK gene expression was especially decreased in obese participants (Table 1) and negatively associated with BMI (Table 3). These results were confirmed in a validation cohort (Table 1) in which PDXK gene expression was negatively correlated with BMI and TMEM26 in VAT, and positively associated with adipogenic (PPARG, $A D I P O Q$, GLUT4 [also known as SLC2A4]), lipid-dropletrelated (CIDEC, PLIN1) and lipogenic (DGAT1) gene expression in both VAT and SAT (Table 4).

To confirm these associations in paired VAT and SAT, all paired samples from both discovery and validation cohorts $(n=114)$ were analysed together. Interestingly, in both VAT and SAT, $P D X K$ gene expression was positively correlated with the expression of adipogenic markers, including ADIPOQ $(r=0.31, p=0.001$ in VAT and $r=0.33, p=0.001$ in SAT), GLUT4 $(r=0.44, p<0.0001$ in VAT and $r=0.50$, $p<0.0001$ in SAT), PLIN1 $(r=0.40, p<0.0001$ in VAT and $r=0.43, p<0.0001$ in SAT $)$ and CIDEC $(r=0.46, p<0.0001$ in VAT and $r=0.51, p<0.0001$ in SAT), and negatively with TMEM26 $(r=-0.29, p=0.004$ in VAT and $r=-0.28, p=0.004$ in SAT).

To further study the potential importance of PLP in adipogenesis at a functional level, SAT PDXK gene expression was studied according to systemic insulin sensitivity (measured using hyperinsulinaemic-euglycaemic clamp), confirming a positive association (Table 4). Bariatric surgery-induced weight loss, which resulted in a significant increase in the expression of adipogenic genes [6], also led to increased $P D X K$ mRNA levels gene expression (Table 5). Of note, the change in $P D X K$ gene expression was positively correlated with the change in adipogenic gene expression (FASN [ $r=0.67, p=0.004]$, PLIN1 [ $r=0.71, p=0.002]$, DGAT1 [ $r=0.74, p=0.001]$, IRS1 [ $r=0.58, p=0.01]$, $P P A R G[r=0.47, p=0.06]$ and $A D I P O Q[r=0.44, p=0.09])$.

\section{PDXK is required for full adipogenic differentiation}

$P D X K$ gene expression increased during adipocyte differentiation of both VAT and SAT adipocytes, with the increase being significantly attenuated in VAT vs SAT adipocyte differentiation (Fig. 2g, h). This is in line with decreased PLP values in VAT in vivo, suggesting a differential response towards the adipogenic effects of vitamin $\mathrm{B}_{6}$ according to anatomical location. Inflammatory stimuli resulted in decreased $P D X K$ 
a

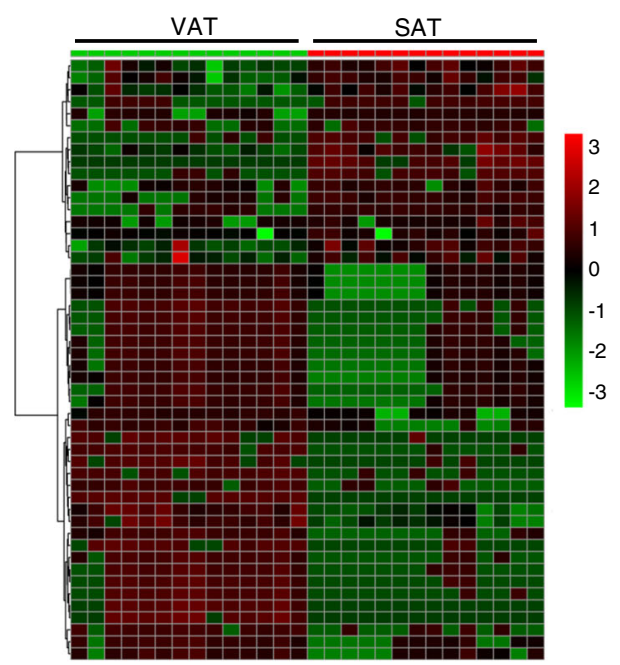

C

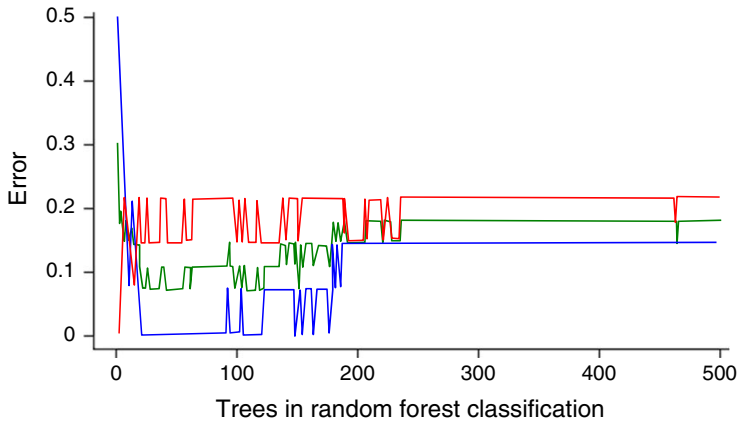

b
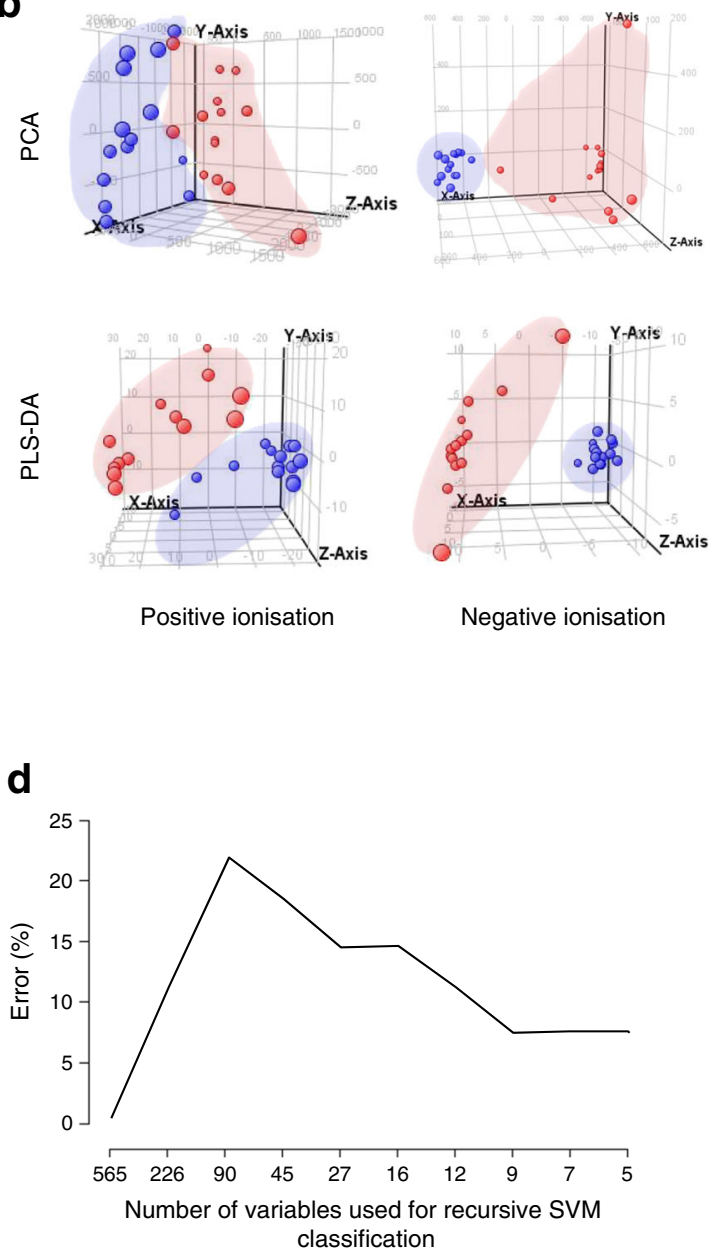

PLS-DA) (b), with red spheres indicating VAT samples and blue spheres SAT samples. (c, d) Multivariate classification procedures performed included random forest analyses (c) and recursive supported vector machine (SVM) classification (d). For random forest classification, an overall classification error of 0.17 (in green) was obtained ( 0.14 for SAT, in blue; 0.21 for VAT, in red)

(Fig. 2j). In line with data from human samples, and reinforcing the importance of PLP in adipogenesis, PLP
Table 2 Metabolites with significantly different concentrations between VAT and SAT

\begin{tabular}{lllll}
\hline Compound & ID (HMDB database) & ID (CAS) & Change (VAT vs SAT) & $p$ value $^{\mathrm{a}}$ \\
\hline Deoxycytidine & HMDB00014 & $951-77-9$ & Down & 0.003421951 \\
Proline & HMDB00162 & $147-85-3$ & Up & 0.012944922 \\
Guaiacol & HMDB01398 & $90-05-1$ & Up & 0.004879887 \\
2-Aminohexadecanoic acid & NI $^{1}$ & $7769-79-1$ & Up & 0.001562683 \\
5 $\alpha$-Androstane-3,17-dione & HMDB11608 & $846-46-8$ & Up & 0.006690529 \\
Farnesal & HMDB60356 & $19317-11-4$ & Up & 0.002234416 \\
Retinoic acid & HMDB02369 & $302-79-4$ & Down & 0.032992125 \\
3-Methylindole & HMDB00466 & $83-34-1$ & Up & 0.00004325 \\
PLP & HMDB01491 & $54-47-7$ & Down & 0.00037100 \\
\hline
\end{tabular}

${ }^{\text {a }}$ Paired $t$ test, at least $p<0.05$ corrected for false discovery rate with Benjamini-Hochberg method NI, not indexed 


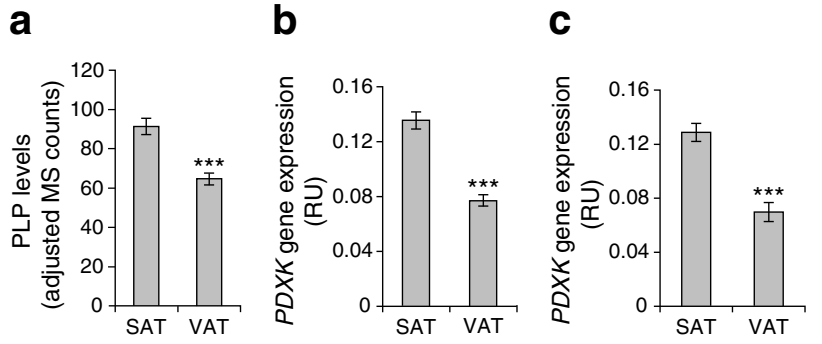

f

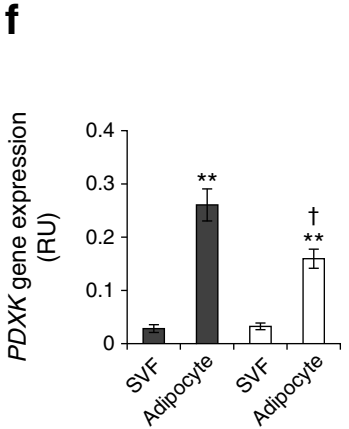

j
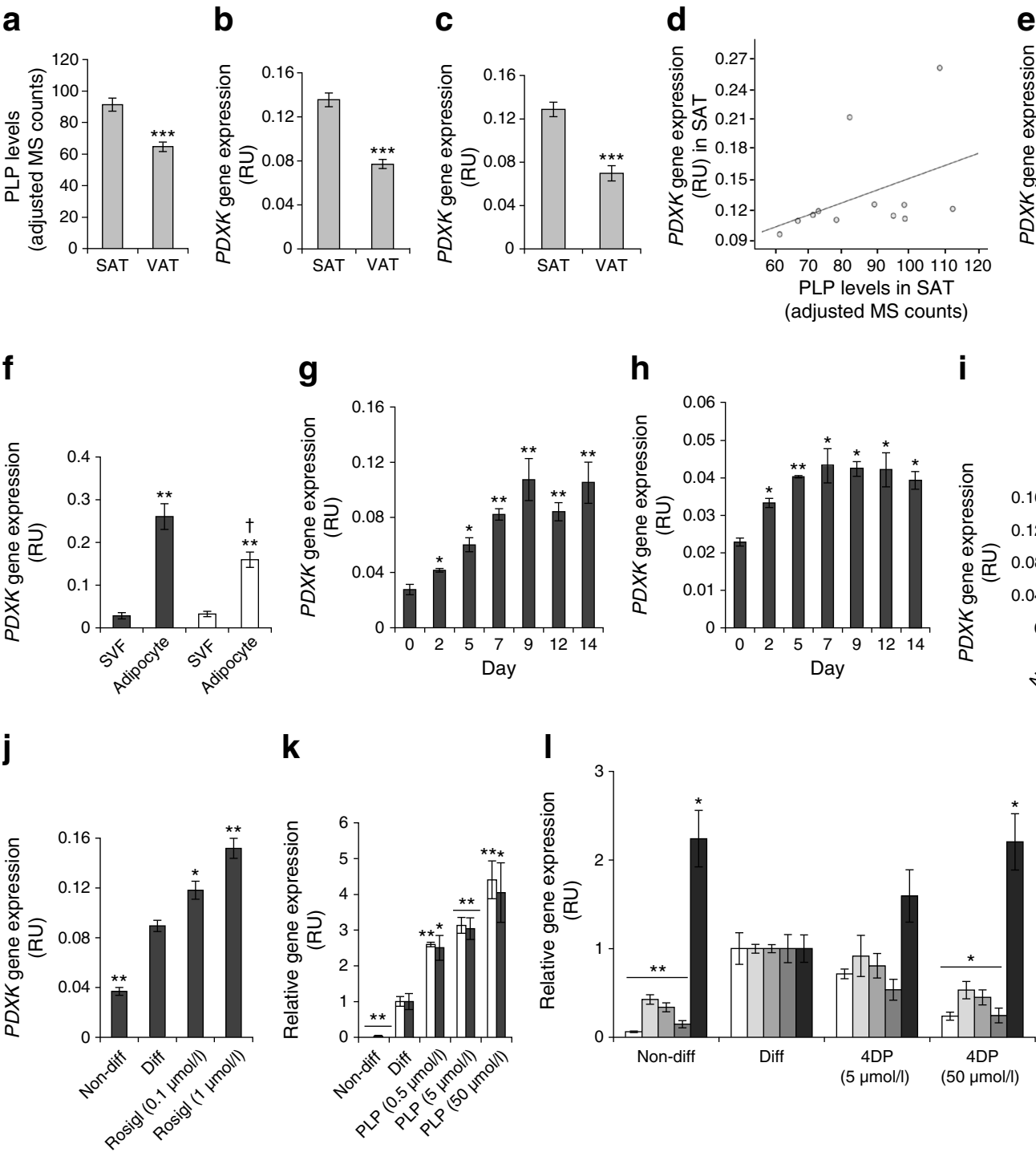

i

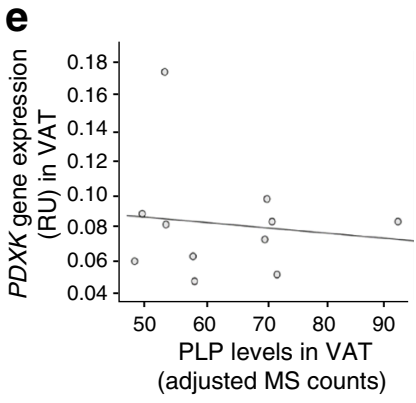

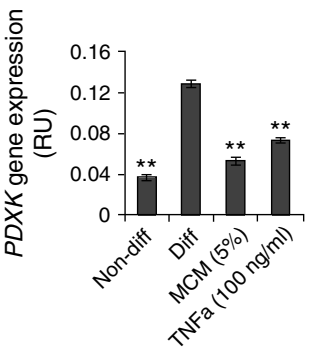

Fig. 2 (a-c) PLP levels were diminished in VAT $(n=14)(\mathbf{a})$, shown in adjusted mass spectrometry (MS) counts, and this was associated with diminished expression of $P D X K$ in VAT in two different cohorts $(\mathbf{b}, \mathbf{c})$ : cohort $1(n=70)(\mathbf{b})$ and cohort $2(n=44)(\mathbf{c}) . * * * p<0.001$ compared with SAT. (d, e) Furthermore, SAT PDXK $(r=0.58, p=0.04)$ (d) but not VAT $(r=-0.07, p=0.8)(\mathbf{e})$ expression correlates with PLP concentrations. Although PLP levels were analysed in all samples, mRNA was available in 12 of these 14 paired samples. Furthermore, PLP levels were very low in one of the VAT samples. (f) $P D X K$ gene expression in adipose tissue fractions in SAT (dark grey bars) and VAT (light grey bars). $* * p<0.01$ compared with SVF; ${ }^{\dagger} p<0.05$ compared with subcutaneous adipocytes. (g, h) PDXK expression during subcutaneous (g) and visceral

administration $(0.5,5$ and $50 \mu \mathrm{mol} / \mathrm{l})$ during early adipogenesis (day 0-2) resulted in a dose-dependent increase in adipogenic gene expression markers (ADIPOQ and GLUT4) (Fig. 2k). On the contrary, administration of 4DP, a PLP antagonist $(50 \mu \mathrm{mol} / \mathrm{l})$, led to a significant reduction in the expression of adipogenic genes (ADIPOQ, PPARG, GLUT4 and $P L I N 1)$ and increased expression of the proinflammatory gene IL6 (Fig. 21). (h) adipocyte differentiation. ${ }^{*} p<0.05$ and $* * p<0.01$ compared with day 0. (i) Effect of inflammatory stimuli on $P D X K$ gene expression during subcutaneous adipocyte differentiation. ${ }^{* *} p<0.01$ compared with differentiated control (Diff). (j) Effect of exposure to a PPAR agonist (rosiglitazone, Rosigl; 0.1 and $1 \mu \mathrm{mol} / \mathrm{l}$ ) on $P D X K$ gene expression in mature adipocytes. ${ }^{*} p<0.05$ and ${ }^{*} * p<0.01$ compared with differentiated control (Diff). (k) Effect of PLP (0.5, 5 and $50 \mu \mathrm{mol} / \mathrm{l})$ administration on adipogenic gene expression, such as $A D I P O Q$ (white bars) and GLUT4 (dark grey bars). (l) Effect of 4DP (5 and $50 \mu \mathrm{mol} / \mathrm{l})$ administration on expression of adipogenesis transcriptional markers, such as $A D I P O Q$, PPARG, GLUT4, PLIN1, and the inflammatory IL6 gene. ${ }^{*} p<0.05$ and $* * p<0.01$ compared with differentiated control (Diff)

\section{Discussion}

Pyridoxal (pyridoxine, vitamin $\mathrm{B}_{6}$ ) kinase is a cytosolic enzyme (EC:2.7.1.35) that phosphorylates vitamin $\mathrm{B}_{6}$, an essential step for the conversion of vitamin $B_{6}$ to PLP (the active form of vitamin $\mathrm{B}_{6}$ ) [20]. PLP acts as a cofactor for more than 140 enzymes, which catalyse multiple biochemical reactions and participate in a wide range of 
Table 3 Correlation analysis of the association between $P D X K$ gene expression and anthropometric and clinical characteristics and selected mRNAs in SAT and VAT from cohort 1, in all participants studied and in paired adipose tissue samples

\begin{tabular}{|c|c|c|c|c|}
\hline \multirow[t]{2}{*}{ Characteristic } & \multicolumn{2}{|c|}{ VAT } & \multicolumn{2}{|c|}{ SAT } \\
\hline & $r$ & $p$ value & $r$ & $p$ value \\
\hline
\end{tabular}

Cohort 1 -all samples ${ }^{\mathrm{a}}$

\begin{tabular}{|c|c|c|c|c|}
\hline \multirow{2}{*}{\multicolumn{5}{|c|}{ Age (years) }} \\
\hline & 0.26 & 0.01 & 0.14 & \\
\hline BMI $\left(\mathrm{kg} / \mathrm{m}^{2}\right)$ & -0.24 & 0.03 & 0.05 & 0.6 \\
\hline Fasting glucose $(\mathrm{mmol} / \mathrm{l})$ & 0.05 & 0.6 & -0.01 & 0.9 \\
\hline Fasting triacylglycerols (mmol/l) & 0.01 & 0.9 & 0.07 & 0.5 \\
\hline HDL-cholesterol (mmol/1) & 0.08 & 0.5 & -0.01 & 0.9 \\
\hline PPARG (RU) & 0.49 & $<0.0001$ & 0.32 & 0.01 \\
\hline$C I D E C$ (RU) & 0.31 & 0.01 & 0.54 & $<0.0001$ \\
\hline PLIN1 (RU) & 0.47 & $<0.0001$ & 0.44 & $<0.0001$ \\
\hline FASN (RU) & 0.26 & 0.01 & 0.25 & 0.02 \\
\hline$A C A C A(\mathrm{RU})$ & 0.25 & 0.01 & 0.27 & 0.01 \\
\hline TMEM26 (RU) & -0.41 & $<0.0001$ & -0.31 & 0.01 \\
\hline$L E P(\mathrm{RU})$ & -0.07 & 0.7 & 0.21 & 0.1 \\
\hline IL6 (RU) & -0.01 & 0.9 & 0.07 & 0.5 \\
\hline$T N F(\mathrm{RU})$ & 0.02 & 0.8 & -0.04 & 0.7 \\
\hline CD68 (RU) & -0.06 & 0.6 & -0.23 & 0.06 \\
\hline ohort 1 - paired samples $^{\mathrm{b}}$ & & & & \\
\hline Age (years) & 0.10 & 0.4 & 0.07 & 0.5 \\
\hline BMI $\left(\mathrm{kg} / \mathrm{m}^{2}\right)$ & -0.23 & 0.05 & 0.07 & 0.5 \\
\hline Fasting glucose (mmol/l) & -0.08 & 0.5 & -0.03 & 0.8 \\
\hline Fasting triacylglycerols $(\mathrm{mmol} / \mathrm{l})$ & -0.22 & 0.06 & 0.14 & 0.2 \\
\hline HDL-cholesterol (mmol/l) & 0.20 & 0.09 & -0.08 & 0.5 \\
\hline$P P A R G(\mathrm{RU})$ & 0.51 & $<0.0001$ & 0.21 & 0.07 \\
\hline$C I D E C$ (RU) & 0.41 & 0.001 & 0.55 & $<0.0001$ \\
\hline PLIN1 (RU) & 0.27 & 0.03 & 0.42 & 0.001 \\
\hline FASN (RU) & 0.34 & 0.005 & 0.23 & 0.05 \\
\hline$A C A C A(\mathrm{RU})$ & 0.32 & 0.01 & 0.21 & 0.07 \\
\hline TMEM26 (RU) & -0.31 & 0.01 & -0.37 & 0.002 \\
\hline$L E P(\mathrm{RU})$ & -0.04 & 0.7 & 0.19 & 0.1 \\
\hline IL6 (RU) & 0.02 & 0.8 & 0.12 & 0.3 \\
\hline$T N F(\mathrm{RU})$ & 0.12 & 0.3 & -0.10 & 0.4 \\
\hline CD68 (RU) & -0.16 & 0.2 & -0.22 & 0.06 \\
\hline
\end{tabular}

a $n=101$ for VAT and 95 for SAT

${ }^{\mathrm{b}} n=70$ for VAT and 70 for SAT

$\mathrm{RU}$, relative gene expression units

metabolic and developmental processes including amino acid, fatty acid and neurotransmitter metabolism [20, 21]. Furthermore, PLP attenuates the production of oxygen reactive species [22] and the formation of advanced glycation end-products [23]. In fact, vitamin B has been used in the treatment of diabetic complications [24], though its use has to be viewed with caution [25].
Table 4 Correlation analysis of the association between PDXK gene expression and anthropometric and clinical characteristics and selected mRNAs in SAT and VAT from cohort 2

\begin{tabular}{|c|c|c|c|c|}
\hline \multirow[t]{2}{*}{ Characteristic } & \multicolumn{2}{|c|}{$\operatorname{VAT}(n=44)$} & \multicolumn{2}{|c|}{ SAT $(n=44)$} \\
\hline & $r$ & $p$ value & $r$ & $p$ value \\
\hline Age (years) & 0.24 & 0.1 & 0.08 & 0.5 \\
\hline BMI $\left(\mathrm{kg} / \mathrm{m}^{2}\right)$ & -0.47 & 0.002 & 0.09 & 0.5 \\
\hline Fasting glucose (mmol/l) & 0.06 & 0.7 & 0.01 & 0.9 \\
\hline$M$ value $\left(\mathrm{mmol} \mathrm{kg}^{-1} \cdot \mathrm{min}^{-1}\right)$ & 0.19 & 0.2 & 0.40 & 0.01 \\
\hline Fasting triacylglycerols $(\mathrm{mmol} / \mathrm{l})$ & -0.08 & 0.6 & -0.02 & 0.8 \\
\hline HDL-cholesterol (mmol/1) & 0.11 & 0.4 & 0.24 & 0.1 \\
\hline$P P A R G(\mathrm{RU})$ & 0.56 & $<0.0001$ & 0.09 & 0.5 \\
\hline CIDEC (RU) & 0.77 & $<0.0001$ & 0.49 & 0.001 \\
\hline PLIN1 (RU) & 0.74 & $<0.0001$ & 0.43 & 0.005 \\
\hline$A D I P O Q(\mathrm{RU})$ & 0.41 & 0.01 & 0.36 & 0.01 \\
\hline GLUT4 (RU) & 0.59 & $<0.0001$ & 0.46 & 0.001 \\
\hline$D G A T 1$ (RU) & 0.61 & $<0.0001$ & 0.63 & $<0.0001$ \\
\hline TMEM26 (RU) & -0.49 & 0.004 & 0.03 & 0.8 \\
\hline IL6 (RU) & -0.18 & 0.3 & -0.22 & 0.2 \\
\hline$T N F(\mathrm{RU})$ & 0.09 & 0.6 & 0.21 & 0.2 \\
\hline
\end{tabular}

$\mathrm{RU}$, relative gene expression units

To the best of our knowledge, this is the first study to demonstrate substantial PLP levels and PDXK gene expression in human adipose tissue, with evident differences between pathogenically relevant distinct anatomical locations. The link between PDXK and adipogenesis was supported by several lines of evidence. First, in line with adipogenic markers [6, 26], PLP levels and PDXK gene expression was decreased in VAT vs SAT and adipocytes, with the associated differences in their adipogenic potential. Second, $P D X K$ gene expression was significantly associated with the expression of adipogenic genes in the discovery and validation cohort. Similar to lipogenic and adipogenic genes $[6,26]$, VAT $P D X K$ mRNA levels were negatively correlated with BMI. Third, bariatric surgery-induced weight loss led to increased $P D X K$ gene expression in positive correlation with adipogenic genes. Fourth, similar to adipogenic genes, $P D X K$ mRNA levels increased during human adipocyte differentiation. Inflammatory conditions attenuated the increase of $P D X K$ mRNA levels during adipocyte differentiation, whereas a PPAR $\gamma$ agonist enhanced PDXK mRNA levels. Finally, the inhibition of PDXK activity (using 4-DP) attenuated adipogenic gene expression during adipocyte differentiation, whereas PLP administration in the early stage of adipocyte differentiation had the opposite effect.

Altogether these data support the notion that in situ production of PLP is required for physiological adipogenesis. Previous knowledge was based on the effects of vitamin $\mathrm{B}_{6}$ per se. A vitamin $\mathrm{B}_{6}$-deficient diet resulted in a significant 
Table 5 Effects of bariatric surgery-induced weight loss on $P D X K$ gene expression, anthropometric and clinical characteristics and biochemical variables in cohort $3(n=18)$

\begin{tabular}{llll}
\hline Characteristic/variable & Baseline & Post-weight loss & $p$ value \\
\hline Age (years) & $49.1 \pm 7.6$ & & \\
BMI $\left(\mathrm{kg} / \mathrm{m}^{2}\right)$ & $43.67 \pm 4.6$ & $29.32 \pm 5.17$ & $<0.0001$ \\
Fasting glucose $(\mathrm{mmol} / \mathrm{l})$ & $5.68 \pm 2.10$ & $4.88 \pm 0.87$ & 0.04 \\
$M$ value $\left(\mathrm{mmol} \mathrm{kg}^{-1} \cdot \mathrm{min}^{-1}\right)$ & $0.023 \pm 0.013$ & $0.033 \pm 0.011$ & 0.001 \\
HDL-cholesterol $(\mathrm{mmol} / \mathrm{l})$ & $1.45 \pm 0.33$ & $1.87 \pm 0.54$ & $<0.0001$ \\
Fasting triacylglycerols $(\mathrm{mmol} / \mathrm{l})$ & $1.33 \pm 0.59$ & $1.01 \pm 0.53$ & 0.001 \\
C-reactive protein $(\mathrm{nmol} / \mathrm{l})$ & $90.91 \pm 7.69$ & $8.45 \pm 5.22$ & $<0.0001$ \\
$P D X K$ gene expression $(\mathrm{RU})$ & $0.112 \pm 0.037$ & $0.151 \pm 0.044$ & 0.001 \\
$A D I P O Q$ gene expression $(\mathrm{RU})$ & $3.43 \pm 1.32$ & $4.58 \pm 1.23$ & 0.01 \\
$I R S 1$ gene expression $(\mathrm{RU})$ & $0.008 \pm 0.004$ & $0.014 \pm 0.005$ & 0.01 \\
\hline
\end{tabular}

Data are means $\pm \mathrm{SD}$. RU, relative gene expression units reduction in adipose tissue and lipogenesis in rat models [16-18]. Vitamin $\mathrm{B}_{6}$ administration increased intracellular lipid accumulation in 3T3-L1 adipocytes [27] and reduced macrophage infiltration and adipose tissue inflammation in mice $[19,28]$.

Current findings show that vitamin $\mathrm{B}_{6}$ needs to be transformed to PLP to show these effects. In fact, PLP induced PPAR $\gamma$ target genes in 3T3-L1 and NHI3T3 cells, stimulating PPAR $\gamma$ transactivation [27]. PPAR $\gamma$ binding sites are co-localised in the promoters of most genes, which change during adipogenesis [29-31]. In the current study, PPAR signalling appeared as a relevant node in the metabolomic network analyses differentiating SAT and VAT. However, other hypotheses on the role of PLP in adipogenesis cannot be dismissed. Huq et al [32] demonstrated that mouse nuclear receptor interacting protein 140 (RIP140) can be modified by PLP conjugation and, in consequence, RIP140 transcriptional co-repressive activity and its physiological function in adipocyte differentiation are enhanced. RIP140 participates in adipocyte fat accumulation and lipogenesis and in the maintenance of white adipocyte phenotype [33, 34]. Otherwise, PLP is a cofactor required for the optimal activity of both mitochondrial and cytoplasmic isoenzymes of serine hydroxymethyltransferase (SHMT1) and (SHMT2) [35, 36]. These enzymes are essential in folate-mediated one-carbon metabolism, which is compartmentalised in the mitochondria and cytoplasm and is known to have an important role in DNA methylation, synthesis and repair [36, 37]. Altered DNA methylation pattern has been recently associated with adipose tissue dysfunction in patients with type 2 diabetes [38]. Current data showing a link between PLP levels and adipogenesis imply that PLP has a possible role in adipose tissue DNA methylation through folate-mediated one-carbon metabolism. In fact, deficiency of vitamin $\mathrm{B}_{6}$ and $\mathrm{B}_{12}$ is known to be associated with altered methylation pattern and decreased DNA stability through inhibition of DNA synthesis and repair [39]. PLP has an important role in the maintenance of genome integrity [40]. Further studies will be required to explore this hypothesis.

Another potentially important finding of the present study was the positive association between SAT $P D X K$ gene expression and insulin sensitivity. Furthermore, $P D X K$ mRNA levels after bariatric surgery-induced weight loss ran in parallel with increased systemic insulin sensitivity in association with the expression of PPAR $\gamma$ target genes [27, 41-43]. In line with these results, plasma PLP levels were found to be negatively associated with insulin resistanceassociated variables (such as $\mathrm{C}$-reactive protein concentration, fasting glucose and $\mathrm{HbA}_{1 c}$ ) in a previous study [44], whereas increased plasma PLP levels correlated with blood glucose reduction in surgically ill patients [45].

In conclusion, the present study suggests a novel role of adipose tissue PDXK activity and PLP levels in adipogenesis and systemic insulin sensitivity, with anatomical differences between SAT and VAT.

Acknowledgements We acknowledge the technical assistance of I. Alonso, E. Loshuertos and O. Rovira (all from the Department of Diabetes, Endocrinology and Nutrition, IdIBGi, Spain).

Funding This work was partially supported by research grants FIS-PI11/00214, FIS-PI11/1543, FIS-PI12/02631, FIS-PI14/00238 and FIS-PI14/00115 from the Instituto de Salud Carlos III, Spain. CIBEROBN Fisiopatología de la Obesidad y Nutrición is an initiative from the Instituto de Salud Carlos III and Fondo Europeo de Desarrollo Regional (FEDER) from Spain.

Duality of interest The authors declare that there is no duality of interest associated with this manuscript.

Contribution statement JMM-N, MJ, MP-O and JMF-R contributed to conception and design, acquisition, analysis and interpretation of data and drafting of the article. FO, GX, WR, EO and RP contributed to acquisition and analysis of data and revised the article critically for important intellectual content. All authors gave their final approval of the version to be published. JMF-R is the guarantor of this work. 


\section{References}

1. Fox CS, Massaro JM, Hoffmann U et al (2007) Abdominal visceral and subcutaneous adipose tissue compartments: association with metabolic risk factors in the Framingham Heart Study. Circulation 116:39-48

2. Jové M, Moreno-Navarrete JM, Pamplona R, Ricart W, PorteroOtín M, Fernández-Real JM (2014) Human omental and subcutaneous adipose tissue exhibit specific lipidomic signatures. FASEB J 28:1071-1081

3. van Harmelen V, Dicker A, Rydén M et al (2002) Increased lipolysis and decreased leptin production by human omental as compared with subcutaneous preadipocytes. Diabetes 51:2029-2036

4. Gesta S, Tseng YH, Kahn CR (2007) Developmental origin of fat: tracking obesity to its source. Cell 131:242-256

5. MacLaren R, Cui W, Simard S, Cianflone K (2008) Influence of obesity and insulin sensitivity on insulin signaling genes in human omental and subcutaneous adipose tissue. J Lipid Res 49:308-323

6. Ortega FJ, Mercader JM, Moreno-Navarrete JM et al (2015) Surgery-induced weight loss is associated with the downregulation of genes targeted by microRNAs in adipose tissue. J Clin Endocrinol Metab 100:E1467-E1476

7. Perrini S, Laviola L, Cignarelli A et al (2008) Fat depot-related differences in gene expression, adiponectin secretion, and insulin action and signalling in human adipocytes differentiated in vitro from precursor stromal cells. Diabetologia 51:155-164

8. Pérez-Pérez R, Ortega-Delgado FJ, García-Santos E et al (2009) Differential proteomics of omental and subcutaneous adipose tissue reflects their unalike biochemical and metabolic properties. J Proteome Res 8:1682-1693

9. Hanzu FA, Vinaixa M, Papageorgiou A et al (2014) Obesity rather than regional fat depots marks the metabolomic pattern of adipose tissue: an untargeted metabolomic approach. Obesity (Silver Spring) 22:698-704

10. Sana TR, Roark JC, Li X, Waddell K, Fischer SM (2008) Molecular formula and METLIN Personal Metabolite Database matching applied to the identification of compounds generated by LC/TOF-MS. J Biomol Tech 19:258-266

11. Jové M, Serrano JC, Ortega N et al (2011) Multicompartmental LCQ-TOF-based metabonomics as an exploratory tool to identify novel pathways affected by polyphenol-rich diets in mice. J Proteome Res 10:3501-3512

12. Xia J, Mandal R, Sinelnikov IV, Broadhurst D, Wishart DS (2012) MetaboAnalyst 2.0 - a comprehensive server for metabolomic data analysis. Nucleic Acids Res 40:W127-W133

13. Kamburov A, Stelzl U, Lehrach H, Herwig R (2013) The ConsensusPathDB interaction database: 2013 update. Nucleic Acids Res 39:D712-D717

14. Moreno-Navarrete JM, Serrano M, Sabater M et al (2013) Study of lactoferrin gene expression in human and mouse adipose tissue, human pre-adipocytes and mouse 3T3-L1 fibroblasts. Association with adipogenic and inflammatory markers. J Nutr Biochem 24: 1266-1275

15. Neville MJ, Collins JM, Gloyn AL, McCarthy MI, Karpe F (2011) Comprehensive human adipose tissue mRNA and microRNA endogenous control selection for quantitative real-time-PCR normalization. Obesity (Silver Spring) 19:888-892

16. Huber AM, Gershoff SN, Hegsted DM (1964) Carbohydrate and fat metabolism and response to insulin in vitamin $\mathrm{B}_{6}$-deficient rats. $\mathrm{J}$ Nutr 82:371-378

17. Ribaya JD, Gershoff SN (1977) Effects of vitamin B6 deficiency on liver, kidney, and adipose tissue enzymes associated with carbohydrate and lipid metabolism, and on glucose uptake by rat epididymal adipose tissue. J Nutr 107:443-452
18. Radhakrishnamurty R, Angel JF, Sabry ZI (1968) Response of lipogenesis to repletion in the pyridoxine-deficient rat. J Nutr 95 341-348

19. Sanada Y, Kumoto T, Suehiro H et al (2013) RASSF6 expression in adipocytes is down-regulated by interaction with macrophages. PLoS One 8, e61931

20. Hellmann H, Mooney S (2010) Vitamin B6: a molecule for human health? Molecules 15:442-459

21. Amadasi A, Bertoldi M, Contestabile R et al (2007) Pyridoxal 5'phosphate enzymes as targets for therapeutic agents. Curr Med Chem 14:1291-1324

22. Ehrenshaft M, Bilski P, Li MY, Chignell CF, Daub ME (1999) A highly conserved sequence is a novel gene involved in de novo vitamin B6 biosynthesis. Proc Natl Acad Sci U S A 96:9374-9378

23. Booth AA, Khalifah RG, Todd P, Hudson BG (1997) In vitro kinetic studies of formation of antigenic advanced glycation end products (AGEs). Novel inhibition of post-Amadori glycation pathways. J Biol Chem 272:5430-5437

24. House AA, Eliasziw M, Cattran DC et al (2010) Effect of B-vitamin therapy on progression of diabetic nephropathy: a randomized controlled trial. JAMA 303:1603-1609

25. Thornalley PJ, Rabbani N (2010) Therapy: vitamin $\mathrm{B}_{6}, \mathrm{~B}_{9}$ and $\mathrm{B}_{12}$ in diabetic nephropathy — beware. Nat Rev Endocrinol 6:477-478

26. Ortega FJ, Mayas D, Moreno-Navarrete JM et al (2010) The gene expression of the main lipogenic enzymes is downregulated in visceral adipose tissue of obese subjects. Obesity (Silver Spring) 18: 13-20

27. Yanaka N, Kanda M, Toya K, Suehiro H, Kato N (2011) Vitamin B6 regulates mRNA expression of peroxisome proliferatoractivated receptor- $\gamma$ target genes. Exp Ther Med 2:419-424

28. Sanada Y, Kumoto T, Suehiro H et al (2014) IкB kinase epsilon expression in adipocytes is upregulated by interaction with macrophages. Biosci Biotechnol Biochem 78:1357-1362

29. Lefterova MI, Zhang Y, Steger DJ et al (2008) PPAR $\gamma$ and C/EBP factors orchestrate adipocyte biology via adjacent binding on a genome-wide scale. Genes Dev 22:2941-2952

30. Rosen ED, Hsu CH, Wang $\mathrm{X}$ et al (2002) C/EBP $\alpha$ induces adipogenesis through PPAR $\gamma$ : a unified pathway. Genes Dev 16:22-26

31. Tontonoz P, Hu E, Spiegelman BM (1994) Stimulation of adipogenesis in fibroblasts by PPAR $\gamma 2$, a lipid-activated transcription factor. Cell 79:1147-1156

32. Huq MD, Tsai NP, Lin YP, Higgins L, Wei LN (2007) Vitamin $B_{6}$ conjugation to nuclear corepressor RIP140 and its role in gene regulation. Nat Chem Biol 3:161-165

33. Leonardsson G, Steel JH, Christian M et al (2004) Nuclear receptor corepressor RIP140 regulates fat accumulation. Proc Natl Acad Sci U S A 101:8437-8442

34. Christian M, Kiskinis E, Debevec D, Leonardsson G, White R, Parker MG (2005) RIP140-targeted repression of gene expression in adipocytes. Mol Cell Biol 25:9383-9391

35. Wu XY, Lu L (2012) Vitamin B6 deficiency, genome instability and cancer. Asian Pac J Cancer Prev 13:5333-5338

36. Perry C, Yu S, Chen J, Matharu KS, Stover PJ (2007) Effect of vitamin $\mathrm{B}_{6}$ availability on serine hydroxymethyltransferase in MCF-7 cells. Arch Biochem Biophys 462:21-27

37. Nichols TW Jr, Gaiteri C (2014) Morton's foot and pyridoxal 5'phosphate deficiency: genetically linked traits. Med Hypotheses 83: 644-648

38. Nilsson E, Jansson PA, Perfilyev A et al (2014) Altered DNA methylation and differential expression of genes influencing metabolism and inflammation in adipose tissue from subjects with type 2 diabetes. Diabetes 63:2962-2976

39. Abbenhardt C, Miller JW, Song X et al (2014) Biomarkers of onecarbon metabolism are associated with biomarkers of inflammation in women. J Nutr 144:714-721 
40. Marzio A, Merigliano C, Gatti M, Vernì F (2014) Sugar and chromosome stability: clastogenic effects of sugars in vitamin B6deficient cells. PLoS Genet 10, e1004199

41. Verreth W, de Keyzer D, Pelat M et al (2004) Weight-lossassociated induction of peroxisome proliferator-activated receptor- $\alpha$ and peroxisome proliferator-activated receptor- $\gamma$ correlate with reduced atherosclerosis and improved cardiovascular function in obese insulin-resistant mice. Circulation 110:3259-3269

42. Petridou A, Tsalouhidou S, Tsalis G, Schulz T, Michna H, Mougios V (2007) Long-term exercise increases the DNA binding activity of peroxisome proliferator-activated receptor $\gamma$ in rat adipose tissue. Metabolism 56:1029-1036
43. Floyd ZE, Stephens JM (2012) Controlling a master switch of adipocyte development and insulin sensitivity: covalent modifications of PPAR $\gamma$. Biochim Biophys Acta 1822:1090-1095

44. Shen J, Lai CQ, Mattei J, Ordovas JM, Tucker KL (2010) Association of vitamin B-6 status with inflammation, oxidative stress, and chronic inflammatory conditions: the Boston Puerto Rican Health Study. Am J Clin Nutr 91:337-342

45. Hou CT, Wu YH, Huang PN, Cheng CH, Huang YC (2011) Higher plasma pyridoxal 5'-phosphate is associated with better blood glucose responses in critically ill surgical patients with inadequate vitamin B-6 status. Clin Nutr 30:478-483 